\title{
HEALTH-FUNCTION INDICATORS FOR THE PREDICTION OF ELDERLY FRAILTY
}

\author{
I-C. Lee ${ }^{1}$, Y.-H. Chiu', I-N. Lee ${ }^{1}$, C.-Y.Lee
}

\begin{abstract}
Objectives: It is crucially worth noticing of how to assess elderly frailty in recent years. This study explores 16 common indicators of health function to investigate the relationship between these indicators and frailty. It ranks the indicators as reference for frailty assessments. Design: Cross-sectional study. Setting: Regional frailty study. Participants : The sample comprised 597 elderly people who residence in the community. Measurements: This study commenced in 2012. By June 2014, 597 people aged over 65 years participated in this study. With the permission of the subjects, the trained interviewer conducted a face-to-face survey and measured the subjects' walking speed and the strength of their grip. The statistical methods were t-test, Chi-square, logistic regression analysis and the decision tree. Results: In this study, there is $31.7 \%$ of elderly demonstrating the symptoms of frailty. Of the health-function indicators, the relationship between decreased appetite and frailty is the strongest, followed by IADL disability, declining cognitive function, malnutrition and pain. Poor eyesight and falling do not show a significant relationship to frailty. Conclusion: Among 16 health-function indicators, the association between nutritional problems and frailty in elderly people is the most significant. Future assessments of frailty should consider the importance of health-function indicators in order to enhance the scope. Screening at-risk elderly people for potential frailty will enable proper health-care planning to achieve the goal of healthy ageing.
\end{abstract}

Key words: Decision tree , elderly, frailty, health-function, nutrition.

\section{Introduction}

The rapid growth of the elderly population has become the trend in many countries in the world. In 2012, there is $11 \%$ of total population aged over 65 years in Taiwan, with the Aging Index of 76.2\% [AI = (population aged over 65 years/population aged under 14 years)x100]. For now, Taiwan could be considered as having the fastest aging speed of population in the world. In the future, the elderly will become the most important group in Taiwan. According to data from the Ministry of Health and Welfare (2012),11\% of people in Taiwan were 65 years or older; however, their medical expenditure was $35 \%$.Further, during the past ten years, the consumption of medical resources increased to $121 \%$. With an increase in the number of elderly people, the health of the elderly becomes an extremely important issue.

1. Department of Healthcare Administration and Medical Informatics, Kaohsiung Medical University, Kaohsiung, Taiwan; 2. Department of Family Medicine, Kaohsiung Medical University Chung-Ho, Memorial Hospital, Kaohsiung, Taiwan.

Corresponding Author: I-Nong Lee, Department of Healthcare Administration and Medical Informatics, Kaohsiung Medical University, 100, Shih-Chuan 1st Road, Kaohsiung 807, Taiwan (R.O.C.). Email: leei@kmu.edu.tw, TEL: 886-7-3121101 ext.2648, FAX: 886-7-313-7487
Recently, more and more attention has been put on the association of frailty and health of elderly. Pel-littel et al. (2009) suggested that when the elderly have healthrelated or other problems, it might only require one sudden breakdown to precipitate more severe situations (1). Elderly people who have health problems can be called frail. Their general functioning and health might deteriorate rapidly in a short period of time, affecting their ability to be independent and autonomous. According to Palmer (1999), physically frail elderly people were a high risk for function degeneration and the necessity of long-term care (2). Elderly frailty is associated with function degeneration, decreased quality of life and increased utilization of medical resources $(3,4)$. Further, many studies have indicated that frailty is related to diabetes, cardiovascular disease and dementia $[(5,6)$. Unlike clinical diseases which are based on standard indicators, definitions and measurement tools for frailty are not consistent. There are several tools to measure frailty. For instance, Rockwood et al.(2005) proposed 70 clinical symptoms related to diseases; the total number of symptoms present indicates the degree frailty (7). Fried et al.(2001) introduced five indicators: unintentional weight loss, weak grip, weakness, slowness and limited physical activity; a person displaying three of these indicators 
would be considered to be frail. Most international studies measure frailty according to the indicators proposed by Fried (2001) (8).

However, these indicators might not be globally suitable to use in all countries. For instance, an unintentional ten-pound weight loss in the past year is considered to be a symptom of frailty. In Asia, elderly people are generally thin and have little body fat; therefore, a ten-pound loss of weight would be considered to be serious (9). Despite of Fried's five indicators, there is no other diagnosis indicators of frailty have been commonly accepted and standardized. Thus, whether any other health function indicators may use to early detect the frailty remains unknown and is worth to clarify. Therefore, the aims of this study are the following: (1) to investigate the genotype of elderly frailty in Taiwan; (2) to collate current common health-related or functional scales, such as assessments of insomnia or nutrition, in order to investigate the relationship between healthfunction indicators and frailty and develop indicators of frailty.

\section{Materials and Methods}

This study commenced in 2012. By June 2014, 597 people aged over 65 years participated in this study. Due to the constraints of limited funds and manpower, only one administrative district of Kaohsiung City was selected. The researcher selected the places where the elderly tended to congregate for activities. With the permission of the subjects, the trained interviewer conducted a face-to-face survey and measured the subjects' walking speed and the strength of their grip. This study was approved by the Institutional Review Board of Kaohsiung Medical University Chung-Ho Memorial Hospital (KMUH-IRB-20120196). The study design, methodological procedure and administrative protocol were carried out in accordance with the ethical approved guidelines. Informed consent was obtained from all subjects prior to data collection.

The research tool used was a structured questionnaire designed by the research team. The questionnaire included not only questions asking basic information, but also questions that investigated current common health functions or scales. Based on the aims of the research, statistical analysis was conducted on some items of the questionnaire. The analytical variables are given below:

(1) Demographic characteristics: age, gender, location and educational level.

(2) Frailty: The indicators of frailty use in this study have been modified from the indicators proposed by Fried et al. (2001), and in hence, these modified indicators for the indication of frailty have good validity as well (10). We assessed frailty according to unintentional weight loss, fatigue, weakness and walking speed. A positive response to "unintentional weight loss in the past three months" and "exhaustion in the past three months", meant the subjects have symptoms of unintentional weight loss and fatigue. Weakness was assessed by grip strength. Since males and females have different levels of grip strength, the researcher divided the subjects into two groups. Follow the standard set by Fried (2001), in each group, the $20 \%$ of subjects with the weakest grip were designated as having weakness. To measure walking speed, the most common way used is the time taken for the subjects to walk three meters. Since height is related to walking speed, the subjects were divided into either a tall group or a short group, according to their height. Refers to Fried's standard, in each group, the $20 \%$ of subjects with the slowest walking speed were designated as being slow walkers.

In the Fried's definition, a person displaying three of these five indicators would be categorized as "frail" person. Meanwhile, a person displaying one or two of these five indicators would be categorized as "pre-frail" person. There are four indicators used to assess frailty in this study. In this study, the subjects who displayed two or more symptoms of frailty were considered to be "frail" and also apparently demonstrated less healthy in general, whereas those with one or no symptom were considered to be "normal" (10).

(3)Health function: there are 16 health-function indicators consist of three aspects of health status in physical, mental and social domains. Indicators are pain, Activities of Daily Life(ADL), Charlson score(CCI), Instrumental Activities of Daily Life(IADL), malnutrition, reduced appetite, falling, poor vision, poor hearing, incontinence, insomnia, declining cognitive function, depression, role functioning-physical (RP), role functioning-emotional (RE) and social functioning (SF) on the MOS 36-Item Short-Form General Health Survey Measures (SF-36) developed by Ware et al. (1992) indicates participative capacity in social activities (11). Please refer to the Table 1 for the detail descriptions of all items and scoring information of subdomains.

In order to clarify which indicators can be used to predict frailty, univariate

analysis, multivariate analysis and decision trees were performed to assess the importance of health function indicators (i.e., independent variable) on the prediction of frailty (i.e., dependent variable). SPSS (Statistical Product and Service Solutions)19.0 was applied to run the univariate analysis (i.e., t-test, chi-square test), and multivariate analysis (i.e., logistic regression). J48 decision trees running on the Weka3.5 data mining software were applied to identify important health-function variables related to frailty (12). All the significance tests and classification results of each variable were ranked and compared separately with individual methods. There will be prioritized and ranked when the statistic results reach the significant level $(\mathrm{P}<0.05)$. Based on the ranking of degree of significance ( $\mathrm{P}$ value), in the results of the univariate analysis, 1 means the significance is the highest $(\mathrm{P}<0.001)$. Based on the ranking of OR(odds ratio) value, in the results of the multivariate analysis, 1 means the 
highest OR value. In decision-tree analysis, ranking is according to the level-order that variable displays on decision tree (i.e., 1 means the variable that displays on the first level of decision tree). A lower ranked variable indicates a stronger relationship with frailty. The rank of 16 will be noted to the indicator when the statistic results do not reach the significant level $(P>0.05)$. In sum of these three numbers of ranking, the indicator with the smaller sum was considered to be more important on the prediction of frailty. This multiple-analysis approach was used to decrease inconsistencies as a result of the analysis methods and data.

\section{Results}

According to the genotype of frailty in this study, fatigue was the most common symptom of frailty, with $74.2 \%$ of the subjects reporting that they experienced fatigue. This is followed by slow walking $(22.6 \%)$, weakness $(19.1 \%)$ and unintentional weight loss (12.7\%). Considering the subjects' performance in these four indicators, $31.7 \%$ of elderly people fell into the frail group. Compared with the normal group, those in the frail group are, on average, older (78.2 years) and have a lower level of education. Most are illiterate or went no further than elementary school (19\% and 51.3\%). Frailty is not significantly associated with gender and place of birth.

Using univariate analysis, this study explored the relationship between frailty and health-function indicators. The results (Table 2) show that CCI, falling, reduced vision, incontinence and depression and not significantly associated with frailty. The other 11 health-function indicators are related to frailty. Subjects who fall into the frail group have an inferior outcome of health-function indicators. Based on the logistic regression model (Table 3 ), after adjusting the demographic characteristics, the researcher included all health-function indicators in the model for calculation. It was demonstrated that the evidence of frailty would be more likely if elderly people presented IADL disability, malnutrition, reduced appetite or declining cognitive function. For instance, those with a reduced appetite during the previous three month have a 4.85 higher probability of becoming frail compared to those with a normal appetite.

Using univariate analysis, multivariate analysis and a decision tree, this study reviewed degrees of the relationship between 16 health-function indicators and frailty. According to the results shown in Table 4, the relationship between reduced appetite and frailty is the highest. The total ranking figure is three. This means that when using different statistical methods, the ranking of the indicator is always the first. After reduced appetite, IADL disability, declining cognitive function, malnutrition and pain are the next most important indicators. In these three analyses, the sum of indicator ranking (falling and poor vision) is 48 which indicate that their relationship with frailty is the weakest.

Table 1

The 16 health-function indicators and their definition

\begin{tabular}{|c|c|}
\hline Variables & Definition \\
\hline Pain & $\begin{array}{l}\text { A } 10 \text {-point scale to measure the degree of pain. A higher } \\
\text { score means more pain is experienced. }\end{array}$ \\
\hline ADL & $\begin{array}{l}\text { Measurements using the ADL scale. A higher score } \\
\text { means the elderly are more capable of dealing with daily } \\
\text { activities }\end{array}$ \\
\hline $\mathrm{CCI}$ & $\begin{array}{l}\text { Charlson score was computed. A higher score means } \\
\text { more severe comorbidity. }\end{array}$ \\
\hline IADL & $\begin{array}{l}\text { Measurements using the IADL scale. IADL disability } \\
\text { is diagnosed if any of the IADL activities can only be } \\
\text { completed with others' help. }\end{array}$ \\
\hline Malnutrition & $\begin{array}{l}\text { Measurement with Part I of Mini Nutritional Assessment } \\
\text { (MNA). Total score } \leqq 11 \text { means the possibility of } \\
\text { malnutrition. }\end{array}$ \\
\hline Reduced appetite & $\begin{array}{l}\text { Question of whether reduced appetite has occurred in the } \\
\text { past three months is asked. }\end{array}$ \\
\hline Falling & $\begin{array}{l}\text { Question of whether falls occurs in the past three months } \\
\text { is asked. }\end{array}$ \\
\hline Poor vision & $\begin{array}{l}\text { Question of whether current vision affects the } \\
\text { performance of daily activities is asked. }\end{array}$ \\
\hline Poor hearing & $\begin{array}{l}\text { Question of whether current hearing affects the } \\
\text { performance of daily activities is asked. }\end{array}$ \\
\hline Incontinence & $\begin{array}{l}\text { Question of whether incontinence has occurred in the past } \\
\text { three months is asked. }\end{array}$ \\
\hline Insomnia & $\begin{array}{l}\text { Question of whether insomnia has occurred in the past } \\
\text { three months is asked. }\end{array}$ \\
\hline $\begin{array}{l}\text { Declining } \\
\text { cognitive function }\end{array}$ & $\begin{array}{l}\text { Measurement using the AD- } 8 \text { scale. Total score } \geqq 2 \\
\text { indicates declining cognitive function. }\end{array}$ \\
\hline Depression & $\begin{array}{l}\text { Measurement using the Geriatric Depression Scale (GDS- } \\
15 \text { ). Total score } \geqq 5 \text { indicates depression is likely. }\end{array}$ \\
\hline $\mathrm{SF} / \mathrm{RP} / \mathrm{RE}$ & $\begin{array}{l}\text { Measure with the SF-36. Higher scores indicate better } \\
\text { social participation. }\end{array}$ \\
\hline
\end{tabular}

ADL:Activities of Daily Life; CCI:Charlson score; IADL:Instrumental Activities of Daily Life; RP:role functioning-physical; RE :role functioning-emotional; SF:social functioning

\section{Discussion}

According to the study, the percentage of people with symptoms of frailty represent a broad range ( $4 \%$ to $80 \%$ ) (13-15). As people grow older, the presence of symptoms of frailty will increase. Elderly people who live in communities show fewer symptoms than people who receive out-patient treatment or who live in institutions. The subjects used in this study were elderly people in a community of whom $31.7 \%$ displayed symptoms of frailty. This is higher than the figures from other studies. Most foreign literature adopts Fried's five indicators and divides elderly people into groups of normal, prefrail and frail. This study selected four indicators and allocated subjects into either a normal group or a frail group. Therefore, the group consisting of frail people may include those who are diagnosed as being pre-frail, thus increasing the percentage of being frailty. However, by 
the dividing the subjects into these two groups, we can recognize that those people identified as being frail are "less healthy" than those in the normal group.

Table 2

Frailty and health-function indicators

\begin{tabular}{|c|c|c|c|}
\hline Variables & Normal & Frail & $\mathbf{P}$ \\
\hline & N/Mean (\%/SD) & N/Mean (\%/SD) & \\
\hline Scores of pain & $1.36(1.97)$ & $2.08(2.20)$ & $<0.001^{\mathrm{a}}$ \\
\hline $\mathrm{ADL}$ & 98.40(3.89) & $96.64(10.21)$ & $0.024^{a}$ \\
\hline CCI & $0.25(0.58)$ & $0.32(0.91)$ & $0.366^{\mathrm{a}}$ \\
\hline \multicolumn{4}{|l|}{ IADL } \\
\hline Disability & $45(12.7)$ & $54(28.7)$ & $<0.001^{\mathrm{b}}$ \\
\hline Normal & $309(87.3)$ & 134(71.3) & \\
\hline \multicolumn{4}{|l|}{ Malnutrition } \\
\hline Yes & $76(24.0)$ & $79(50.3)$ & $<0.001^{\mathrm{b}}$ \\
\hline No & $241(76.0)$ & $78(49.7)$ & \\
\hline \multicolumn{4}{|c|}{ Reduced appetite } \\
\hline Yes & $5(1.4)$ & 18(9.5) & $<0.001^{\mathrm{b}}$ \\
\hline No & 351(98.6) & $171(90.5)$ & \\
\hline \multicolumn{4}{|l|}{ Falling } \\
\hline Yes & $38(10.7)$ & 18(9.5) & $0.767^{\mathrm{b}}$ \\
\hline No & 318(89.3) & $171(90.5)$ & \\
\hline Poor vision & & & $0.368^{\mathrm{b}}$ \\
\hline Yes & $67(18.8)$ & $42(22.3)$ & \\
\hline No & $289(81.2)$ & $146(77.7)$ & \\
\hline \multicolumn{4}{|l|}{ Poor hearing } \\
\hline Yes & $46(12.9)$ & $43(22.8)$ & $0.005^{\mathrm{b}}$ \\
\hline No & $310(87.1)$ & $146(77.2)$ & \\
\hline \multicolumn{4}{|l|}{ Incontinence } \\
\hline Yes & 11(3.3) & $11(6.1)$ & $0.168^{\mathrm{b}}$ \\
\hline No & $325(96.7)$ & 168(93.9) & \\
\hline \multicolumn{4}{|l|}{ Insomnia } \\
\hline Yes & $116(32.9)$ & $79(42.0)$ & $0.039^{\mathrm{b}}$ \\
\hline No & $237(67.1)$ & 109(58.0) & \\
\hline \multicolumn{4}{|c|}{ Declining cognitive function } \\
\hline Yes & $53(15.1)$ & $48(25.7)$ & $0.004^{\mathrm{b}}$ \\
\hline No & 299(84.9) & 139(74.3) & \\
\hline \multicolumn{4}{|l|}{ Depression } \\
\hline Yes & $13(3.7)$ & $13(7.1)$ & $0.093^{b}$ \\
\hline No & $337(96.3)$ & $170(92.9)$ & \\
\hline SF & 90.11(15.39) & $84.38(18.58)$ & $<0.001^{\mathrm{a}}$ \\
\hline $\mathrm{RP}$ & $90.73(25.28)$ & $76.72(39.20)$ & $<0.001^{\mathrm{a}}$ \\
\hline $\mathrm{RE}$ & 95.95(17.18) & $88.54(28.63)$ & $0.001^{\mathrm{a}}$ \\
\hline
\end{tabular}

a: Analytical result of t-test; $b$ : Analytical result of Chi-square
Table 3

The logistic regression model of frailty

\begin{tabular}{lrrrr}
\hline Variables & B & OR & \multicolumn{2}{c}{$\begin{array}{r}\text { 95\% confidence interval } \\
\text { lower limit }\end{array}$} \\
& & & upper limit \\
\hline Scores of pain* & 0.10 & 1.11 & 0.96 & 1.27 \\
ADL $^{*}$ & 0.02 & 1.02 & 0.97 & 1.08 \\
CCI $^{*}$ & -0.23 & 0.79 & 0.55 & 1.15 \\
IADL disability & 0.73 & 2.08 & 1.04 & 4.14 \\
Malnutrition & 0.84 & 2.32 & 1.34 & 4.04 \\
Reduced appetite & 1.58 & 4.85 & 1.12 & 21.03 \\
Falling & -0.10 & 0.90 & 0.39 & 2.09 \\
Poor vision & -0.20 & 0.82 & 0.41 & 1.64 \\
Poor hearing & 0.32 & 1.38 & 0.66 & 2.91 \\
Incontinence & 0.81 & 2.25 & 0.59 & 8.63 \\
Insomnia & 0.36 & 1.43 & 0.81 & 2.53 \\
$\begin{array}{l}\text { Declining cognitive } \\
\text { function }\end{array}$ & 0.69 & 1.99 & 1.03 & 3.83 \\
Depression & & & & \\
SF* & -1.36 & 0.26 & 0.06 & 1.16 \\
RP* & -0.01 & 0.99 & 0.97 & 1.01 \\
RE* & -0.003 & 1.00 & 0.99 & 1.01 \\
\hline Data of demographics were adjusted; ${ }^{*}$ It is a continuity variable. Reference \\
groups of other variables refer to those with normal IADL and without the \\
problems of nutrition, reduced appetite, falling, poor vision, poor hearing, \\
incontinence, insomnia, declining cognitive function and depression
\end{tabular}

The 16 health function indicators used in this study are commonly used to assess the health of the elderly. According to the findings in this study, most of the indicators are associated with frailty which are consistent with the literature. When elderly people experience loss of appetite and consequent malnutrition, the probability of them being frail will be higher $(15,16)$. People who have been identified as being frail show higher scores on pain measurements, indicating that they experience more pain than normal people (6). The ability to manage daily activities is included in ADL and IADL. The results show that frail people are significantly affected in these two indicators $(5,17,18)$. Many frail older people experience insomnia or declining cognitive function $(19,20)$. As well as the physical and psychological parameters, social participative capacity (RP, RE and SF) is significantly related to frailty. Frail elderly people have lower scores in three indicators, compared with the normal group $(21,22)$. Although this study demonstrates that CCI, incontinence, depression, falling and reduced vision are less significantly related to frailness, some research associates these indicators with frailty. Those who are frail have higher scores of CCI, compared with the normal group. This means that frail people tend to get ill more often and that their illnesses are more serious than those in the normal group (14). In comparison with the normal group, the elderly in the frail group display a greater 
Table 4

Importance ranking of 16 health-function indicators to predict frailty

\begin{tabular}{|c|c|c|c|c|}
\hline Variables & Univariate analysis (a) & Multivariate analysis (b) & $\begin{array}{l}\text { Decision-tree analysis } \\
\text { (c) }\end{array}$ & Total number of ranking \\
\hline Reduced appetite & 1 & 1 & 1 & 3 \\
\hline IADL disability & 1 & 3 & 2 & 6 \\
\hline Declining cognitive function & 3 & 4 & 7 & 14 \\
\hline Malnutrition & 1 & 2 & 16 & 19 \\
\hline Pain & 1 & 16 & 4 & 21 \\
\hline $\mathrm{SF}$ & 1 & 16 & 4 & 21 \\
\hline $\mathrm{RP}$ & 1 & 16 & 4 & 21 \\
\hline $\mathrm{RE}$ & 2 & 16 & 3 & 21 \\
\hline ADL & 5 & 16 & 3 & 24 \\
\hline Insomnia & 6 & 16 & 2 & 24 \\
\hline Poor hearing & 4 & 16 & 5 & 25 \\
\hline $\mathrm{CCI}$ & 16 & 16 & 4 & 36 \\
\hline Depression & 16 & 16 & 5 & 37 \\
\hline Incontinence & 16 & 16 & 6 & 38 \\
\hline Falling & 16 & 16 & 16 & 48 \\
\hline Poor vision & 16 & 16 & 16 & 48 \\
\hline
\end{tabular}

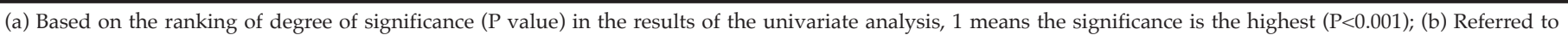

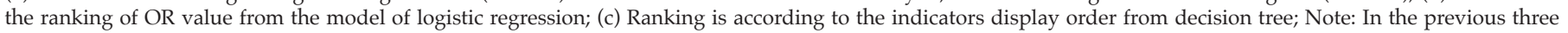

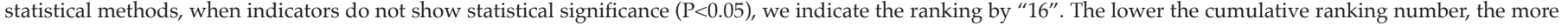
important the indicators!

probability of having health problems, falling, reduced vision or hearing, incontinence, and depression $(5,18$, 23-24).

As well as investigating the relationship between health functions and frailty by means of different statistical analysis methods, this study explored the importance of health-function indicators to predict frailty. According to the results, when elderly people have experienced a reduction in appetite in the past three months, the probability of them becoming frail significantly increases. In addition, when the elderly are malnourished, the probability of frailness is not low; this is fourth on the importance ranking. Therefore, the relationship between nutrition, appetite and frailty is the highest. Malnutrition in the elderly is extremely common, which significantly influences their overall health (25-27). This is due to the slowing down of physical functionality, affecting the person's chewing, swallowing, digesting, and absorption capabilities (25). As well as this, there can be a lack of motivation in preparing meals $(26,27)$. However, elderly people or their family members usually do not pay attention to their low appetite or malnutrition. Initially, they might show symptoms of frailty such as feeling exhausted, having weakness and walking slowly. If they continue to neglect these symptoms, more serious and complicated health problems could develop. According to the importance ranking of 16 healthfunction indicators shown in Table 4, IADL disability and declining cognitive function fall in the top two and three. Likewise, elderly people with IADL disability and declining cognitive function might not feel unwell (in the same way as those who are malnourished and have decreased appetite) and do not seek medical assistance. In the long term, deterioration of health may occur (28).

Two of the indicators -low vision and falling in the past three months -have the weakest relationship with frailty. This may be due to a more severe health condition caused by falls, such as a fracture and the inability to be independent (29). In such instances, they seek doctors' help. After the intervention of professional medical care, the negative impact on health will be lower; therefore, the relationship with symptoms of frailty will tend to be low.

Although vision and hearing are both sensory capacities, their relationship with frailty is significantly different. The result of this study shows that poor hearing is more strongly associated with frailty than poor sight, but that poor sight is more significant in respect of daily activities. When the elderly are inconvenienced by their poor sight, they will immediately go to see the doctor to improve their sight. In this case, the impact on health will be controlled before the reduced vision impacts the person's frailty. Declining hearing in the elderly might not be noticed immediately. However, ignoring this symptom for too long a period without intervention can lead to more health-related problems. For instance, with difficulties in hearing, an elderly person can 
misunderstand the information about health education, leading to physical discomfort (30).

\section{Conclusions}

In conclusion, although frailty is not an illness, it does demonstrate symptoms that could be considered to be a lack of good health. This study adopts 16 common health-function indicators and analyzes the relationship between all the indicators and frailty. Indicators which are more associated with frailty tend to have less of an impact on elderly people's daily activities or do not cause harm. Take the problems of nutrition (i.e., no appetite, malnutrition) as example, elderly people will not go to the doctor immediately or seek intervention from medical care services. Thus, in the long term, the effect of poor health function will very likely lead to health problems. Compared with illness, symptoms of frailty can be considered to be a warning of potential health problems but the symptoms are usually not noticed by elderly people or their relatives. However, from the perspective of prevention, screening frail elderly people in advance of the development of health problems and providing proper health care intervention will help accomplish the goal of "healthy ageing". Regarding the measurement of frailty, according to the importance ranking of health-function indicators in this study, as well as the indicators proposed by Fried, we include reduced appetite, nutrition, IADL, cognitive function, pain and participation in social activities. These indicators can enhance the scope of the assessment of frailty and increase the precision of an assessment for screening high-risk elderly people. When frailty is identified, proper health care can be planned. Hopefully this screening can reduce the probability of elderly people becoming disabled or bed-ridden and enhance their quality of life in their old age.

Acknowledgements: Sincere appreciation will be given to all individuals who participate in this study.

Ethical Standards: This study was approved by the Institutional Review Board of Kaohsiung Medical University Chung-Ho Memorial Hospital (KMUHIRB-20120196). The study design, methodological procedure and administrative protocol were carried out in accordance with the ethical approved guidelines. Informed consent was obtained from all subjects prior to data collection. All datasets on which the conclusions of the manuscript presented in the main paper.

Conflict of interest: The authors declare no conflict of interest.

\section{References}

1. Pel-Littel RE, Schuurmans MJ, Emmelot-Vonk MH, Verhaar HJ. Frailty: defining and measuring of a concept. J Nutr Health Aging. 2009;13: 390-394.

2. Palmer RM : Acute care. In: Hazzard WR, Blass JP, Ettinger WH Jr, eds, Principles of Geriatric Medicine and Gerontology. 4th ed. New York: McGraw-Hill, 1999: 482-492.

3. Ensrud KE, Ewing SK, Taylor BC, Fink HA, Cawthon PM, Stone KL et al. Comparison of 2 frailty indexes for prediction of falls, disability, fractures, and death in older women. Arch Intern Med. 2008; 68: 382-389.

4. Rochat S, Cumming RG, Blyth F, Creasey H, Handelsman D, Le Couteur DG et al. Frailty and use of health and community services by communitydwelling older men: the Concord Health and Ageing in Men Project. Age Ageing. 2010; 39: 228-233.
5. Mello Ade C, Engstrom EM, Alves LC. Health-related and socio-demographic factors associated with frailty in the elderly: a systematic literature review. Cad Saude Publica. 2014; 30: 1143-1168.

6. Morley JE, Kim MJ, Haren MT, Kevorkian R, Banks WA. Frailty and the aging male. Aging Male. 2005; 8: 135-140.

7. Rockwood K, Song X, MacKnight C, Bergman H, Hogan DB, McDowell I et al. A global clinical measure of fitness and frailty in elderly people. CMAJ 2005; 73: 489-495.

8. Fried LP, Tangen CM, Walston J, Newman AB, Hirsch C, Gottdiener J et al. Cardiovascular Health Study Collaborative Research Group. Frailty in older adults: evidence for a phenotype. J Gerontol A BiolSci Med Sci. 2001; 6: M146-M156.

9. Shih-Ping Chen, Li-Ning Peng, Ming-Hsien Lin, Hsiu-Yun Lai, Shinn-Jang Hwang, Liang-Kung Chen. Evaluating probability of cancer among older people with unexplained, unintentional weight loss. Arch Gerontol Geriatr. 2010; 50: S27-S29.

10. IC Lee, YH Chiu, CY Lee. Exploration of the importance of geriatric frailty on health-related quality of life . Psychogeriatrics. 2016; DOI: 10.1111/ psyg.12179.

11. Ware JE, Sherbourne CD. The MOS 36-ltem short-form health survey (SF-36): I. Conceptual framework and item selection. Med Care. 1992; 30: 473-483.

12. Witten IH, Frank E. Data Mining: Practical machine learning tools and techniques: Morgan Kaufmann. 2011; 11: 454.

13. Gale CR, Cooper C, Aihie Sayer A. Prevalence of frailty and disability: findings from the English Longitudinal Study of Ageing. Age Ageing. 2015; 44: 162-165.

14. Kanwar A, Singh M, Lennon R, Ghanta K, McNallan SM, Roger VL. Frailty and health-related quality of life among residents of long-term care facilit-ies. J Aging Health. 2013; 25: 792-802.

15. Serra-Prat M, Mans E, Palomera E, Clavé P. Gastrointestinal peptides, gastrointestinal motility, and anorexia of aging in frail elderly persons. Neurogastroenterol Motil. 2013; 25: 291-e245.

16. Semba RD, Bartali B, Zhou J, Blaum C, Ko CW, Fried LP. Low serum micronutrient concentrations predict frailty among older women living in the community. J Gerontol A Biol Sci Med Sci. 2006; 61: 594-599.

17. Avila-Funes JA, Helmer C, Amieva H Avila-Funes JA, Helmer C, Amieva H, Barberger-Gateau $\mathrm{P}$ et al. Frailty among community-dwelling elderly people in France: the three-city study. J Gerontol A Biol Sci Med Sci. 2008; 63: 10891096.

18. Sousa AC, Dias RC, Maciel ÁC, Guerra RO. Frailty syndrome and associated factors in community-dwelling elderly in Northeast Brazil. Arch Gerontol Geriatr. 2012; 54: e95-e101.

19. Ensrud KE, Blackwell TL, Redline S, Ancoli-Israel S, Paudel ML, Cawthon PM et al. Sleep disturbances and frailty status in older community-dwelling men. J Am Geriatr Soc. 2009; 57: 2085-2093.

20. Nishiguchi S, Yamada M, Fukutani N,Adachi D, Tashiro Y, Hotta T et al. Differential Association of Frailty With Cognitive Decline and Sarcopenia in Community-Dwelling Older Adults. J Am Med Dir Assoc. 2015; 16: 120-124.

21. Lin CC, Li CI, Chang CK, Liu CS, Lin CH, Meng NH et al. Reduced healthrelated quality of life in elders with frailty: a cross-sectional study of community-dwelling elders in Taiwan. PLoS One. 2011; 6: e21841.

22. Masel MC, Graham JE, Reistetter TA, Markides KS, Ottenbacher KJ. Frailty and health related quality of life in older Mexican Americans. Health Qual Life Outcomes. 2009; 7: 70.

23. Klein BE, Klein R, Knudtson MD, Lee KE. Relationship of measures of frailty to visual function: the Beaver Dam Eye Study. Trans Am Ophthalmol Soc. 2003; 101: 191-199.

24. Makizako H, Shimada H, Doi T, Yoshida D, Anan Y, Tsutsumimoto K et al Physical Frailty Predicts Incident Depressive Symptoms in Elderly People: Prospective Findings From the ObuStudy of Health Promotion for the Elderly. J Am Med Dir Assoc. 2015; 16: 194-9.

25. Poisson P, Laffond T, Campos S, Dupuis V, Bourdel-Marchasson I. Relationships between oral health, dysphagia and undernutrition in hospitalized elderly patients. Gerodontology. 2014. doi: 10.1111/ger.12123.

26. Pereira GF, Bulik CM, Weaver MA, Holland WC, Platts-Mills TF. Malnutrition Among Cognitively Intact, Noncritically Ill Older Adults in the Emergency Department. Ann Emerg Med. 2015; 65: 85-91.

27. Montejano Lozoya AR, Ferrer Diego RM, Clemente Marín G, Martínez Alzamora N, Sanjuan Quiles A, Ferrer Ferrándiz E. Nutrition-related risk factors in autonomous non-institutionalized adult elderly people. Nutr Hosp. 2014; 30: 858-869.

28. d'Orsi E, Xavier AJ, Steptoe A, de Oliveira C, Ramos LR, Orrell M et al. Socioeconomic and lifestyle factors related to instrumental activity of daily living dynamics: results from the English Longitudinal Study of Ageing. J Am Geriatr Soc. 2014; 62: 1630-1639.

29. Butt DA, Mamdani M, Austin PC, Tu K, Gomes T, Glazier RH. The risk of falls on initiation of antihypertensive drugs in the elderly. Osteoporos Int. 2013; 24: 2649-2657.

30. Diao M, Sun J, Jiang T, Tian F, Jia Z, Liu Y et al. Comparison between selfreported hearing and measured hearing thresholds of the elderly in China. Ear Hear. 2014; 35: e228-e232. 